\title{
Effects of TPRS on Very Young Learners' Vocabulary Acquisition
}

\author{
Ketevan Kara ${ }^{1 *}$, Evrim Eveyik-Aydın ${ }^{2}$ \\ ${ }^{1}$ Dragos Bahçeşehir kindergarten, Defne Sk., 34865 Kartal, Istanbul, Turkey \\ ${ }^{2}$ Yeditepe University, Faculty of Education, Department of English Language Teaching, Kayışdağı Cad., 34755 Ataşehir, Istanbul, \\ Turkey 3191
}

Corresponding Author: Ketevan Kara, E-mail: ketevan.lordkipanidze@gmail.com

\section{ARTICLE INFO}

Article history

Received: October 10, 2018

Accepted: January 12, 2019

Published: February 28, 2019

Volume: 10 Issue: 1

Advance access: January 2019

Conflicts of interest: None

Funding: None

\section{Key words:}

EFL,

Teaching Proficiency through Reading and Storytelling (TPRS),

Very Young Learners,

Vocabulary Acquisition,

Receptive and Productive Vocabulary

Knowledge,

Word Frequency,

\begin{abstract}
Teaching Proficiency through Reading and Storytelling (TPRS) aims to provide language learners with considerable amount of comprehensible input through stories for language and literacy development. Although it has already demonstrated high potential with adolescent and adult learners of English, its implementation within the context of very young learners and its impact on their language acquisition is an issue that remains to date underexplored. Therefore, this study aims to investigate the possible effects of TPRS on very young learners' L2 receptive and productive vocabulary acquisition. Nineteen four-year-old kindergarten students in Turkish EFL context constituted a single treatment group of the study. The study had pretest-treatmentimmediate posttest-and delayed posttest design. The target vocabulary was taught following the stages of TPRS and adapting them to the context of very young learners. Data collection included receptive and productive picture tests that were developed and administered in one-to-one sessions with each participating child. The results show that TPRS has a positive effect both on recall and retention of receptive and productive vocabulary. Receptive learning was discovered to benefit from the treatment more than productive learning. Additionally, some vocabulary items were found to be more challenging for children to acquire than the others mostly due to their low frequency. The study suggests that TPRS can be used to teach vocabulary to very young learners as it uses techniques that support their language acquisition. The study also provides guiding suggestions to adapt this method to the context of very young learners.
\end{abstract}

\section{INTRODUCTION}

Turkey is one of the countries where developing competence in English language has long been acknowledged as of great importance. English language education usually starts at the ages of 3-4 in private schools to ensure an early start for exposure to that language following the widely popular "the younger, the better" belief. Teaching English as a foreign language (EFL) to very young learners in a classroom environment, however, is often considered a hard task because of the cognitive, developmental, social, and affective characteristics of these children (Donaldson, 1978; Brewster et al., 2002; Morrison, 1997). First, teachers are challenged to create a peaceful and curiosity-fostering environment supporting their development with meaningful, exploratory and sensory experiences similar to those in their first language acquisition. Second, as 3-to-6 year-old preschoolers are normally not capable of reading and writing, listening and speaking are the main skills focused on to acquire a foreign language, and vocabulary seems to be the key for gaining these skills as the lexical knowledge is crucial in building communicative competence (Schmitt, 2000). However, teaching vocabulary to this age group is a challenge as there are few if any acknowledged teaching materials for preschool ELT (Tunçarslan, 2013; Tabors \& Snow, 2013). In fact, there is no established methodology for teaching English to very young learners within the EFL context of Turkey, as the Ministry of Education does not prescribe any EFL curriculum for this age group. This creates additional difficulties for teachers who end up designing their own teaching materials and activities using the techniques appealing to very young learners, such as songs, games, acting, demonstration, and storytelling. Therefore, as teaching English at kindergarten level gets more important, the need for methodologies with appropriate techniques for very young learners increases.

Teaching Proficiency through Reading and Storytelling (TPRS) approach, which was developed in 1980s by Blaine Ray basically to teach Spanish to L1 speakers of English, may be used effectively with very young learners despite his original intention to use this method with high school students (Ray \& Seely, 2004). Based on the principles of 
Krashen's Natural Approach and Asher's Total Physical Response (TPR), TPRS has the potential to facilitate preschoolers' language acquisition by providing them with plenty of comprehensible input on high frequency vocabulary and structures in a highly contextualized and personalized way. The method uses unique techniques for storytelling, such as making up personalized stories followed by acting out activities, and gives learners multiple opportunities for repetition in a positive learning environment. Although research provides evidence for the effectiveness of TPRS in introducing new L2 vocabulary to adults and adolescents (e.g. Sutijono, 2014; Roberts \& Thomas, 2014; Jebeli, 2012; Castro, 2010; Varguez, 2009; Spangler, 2009; Armstrong, 2008; Perna, 2007; Braunstein, 2006; Davidheiser, 2001), few studies explored the same phenomenon with very young learners (e.g. Gil, 2015; Demir \& Çubukçu, 2014; Li, 2013). Therefore, the current study intends to find if the method yields as successful results with preschoolers as it does with the learners of older ages. More specifically, it investigates the short-term and long-term effects of TPRS implementation on vocabulary acquisition in a preschool setting.

As vocabulary may be acquired in two ways, receptively and productively, this distinction was made in the current study in order to find out whether TPRS has a greater effect on either of them. Productive learning is generally considered as more difficult than receptive learning, as it requires more effort and more complex operations; moreover, receptive use of the new words takes place more often in the classroom, than productive use (Ellis \& Beaton, 1993; Benjamin \& Crow, 2012). Therefore, receptive knowledge was expected to benefit from the treatment more than productive knowledge.

Thus, the study addresses the following research questions:

1. Does TPRS produce a short-term and a long-term effect on very young learners' L2 receptive and productive vocabulary acquisition?

2. Which type of lexical knowledge, receptive or productive, benefits from TPRS instruction more in the context of very young learners' L2 vocabulary acquisition?

Additionally, the study aims to provide guidelines on the use of TPRS as a methodology in kindergarten. For this purpose, the steps of storytelling implementation within TPRS methodology were adapted to the context of very young learners. Lesson plans were designed to teach vocabulary to preschoolers following the underpinnings of TPRS methodology in a way to include activities appropriate for young learners. Hence, the study makes a contribution to the literature on TPRS by demonstrating how it can be used by kindergarten teachers of English to teach L2 vocabulary.

\section{Very Young Learners and Teaching Proficiency through Reading and Storytelling (TPRS)}

Very young learners are considered to be the children who have not yet started their first year of compulsory education at school (Reilly \& Ward, 2003). They haven't developed their motor skills yet, and are illiterate. They are different from older children on a number of characteristics. Among them, Brewster et al. (2002) name their extreme physical activeness, emotional instability, developing L1, short attention span, forgetfulness, egocentrism, and self-orientation. At this age it is important for them to develop a sense of confidence and feel secure to learn. Another essential condition for their learning is enthusiasm, which can be stimulated through various explorative and sensory activities and games. In addition, very young learners are not capable of learning abstract things; they need concrete concepts that would relate to their immediate situation. Their learning style is mostly kinesthetic, therefore, it is necessary for them to touch and see in order to learn (Ormond, 2010; Widodo, 2005; Wright et al., 2007).

Some scholars agree that TPRS provides the right theoretical framework for very young learners to acquire a language by following the principles of Natural Approach and Total Physical Response. On one hand, in line with the former methodology, TPRS emphasizes the importance of comprehension before production as in first language acquisition. On the other hand, it shares Asher's idea that the activation of right hemisphere through physical activities is essential to prepare learners for language processing. In other words, language is acquired through actions and physical responses. Hence, TPRS provides learners with comprehensible input, allows them to go through a silent period before producing the language, encourages physical activities, and creates a safe and stimulating atmosphere in the classroom (Li, 2013). The element of play it includes is essential in early years education and makes the learning possible and enjoyable for young children in a stress-free environment (Gil, 2015).

Moreover, TPRS uses storybooks as the main tools to teach vocabulary and grammar structures. In the literature there is a consensus on the effectiveness of storybook reading in vocabulary acquisition of learners of a variety of ages. Stories expose the learners to unfamiliar words in a meaningful way, and let the teachers introduce new notions and communicate the meaning successfully (Elley, 1989; Penno et al., 2002; Blok, 1999; Collins, 2004; Soleimani \& Akbari, 2013). They provide a context familiar to a child, serve as a source of a large number of learning activities (Brewster et al., 2002), motivate students to listen to target language and to develop positive attitude towards it at the same time (Castro, 2002), bolster the development of learning strategies (Cooper et al., 1992), and provide visualization, which makes the language of book more comprehensible and memorable (Wasik \& Bond, 2001). In studies conducted by Abasi and Soori (2014) and Tunçarslan (2013) storytelling has been shown to have a positive effect on 5-year old and 3-to4 year-old young learners' receptive vocabulary respectively. Tunçarslan explains that not only do the story-based activities provide very young learners with meaningful input, but they also meet their needs by keeping them highly motivated, engaged and entertained.

How are stories used within TPRS then? Unlike other methods and approaches where storytelling is involved, TPRS uses it in its own unique way. The stories are not only told, but also listened to, read, and written. In the meantime, frequent comprehension checks are done through the 
circling technique. In case of lack of comprehension, more pre-teaching is done, and the whole process is slowed down (Ray \& Seely, 2004). There are three main steps followed when implementing storytelling with TPRS principles in the classroom:

1) Establishing meaning. This step includes introduction and pre-teaching of the basic vocabulary items and structures before the storytelling activity. TPRS aims at teaching the most basic words and structures, therefore the target items are selected from the list of the most frequent words of a language, and the most common structures are preferred (Ray \& Seely, 2004). TPRS recommends L1 translation, gestures and Personalized Question Answer (PQA) techniques as possible ways to introduce the new input and practise it. Through PQA the teacher asks the learners personalized questions about the target item to contextualize it, promote their interest and motivation, and provide repetition.

2) Asking a story. This is the core step of TPRS when the storytelling is used to teach the target vocabulary and structures through multiple repetitions. As the story progresses, the students are frequently asked creative and/ or comprehension questions to check comprehension through a technique called 'circling'. This technique involves yes/no, either/or, and wh- questions. In this stage, the students are involved in the creation of the story; they can name the characters, add details, make changes, and even create parallel stories. During the whole process, the story is acted out by the volunteering students who often use props and are directed by the teacher to act the lines accurately. The learners are involved into the learning process, they are active and feel comfortable. Being concentrated on the plot and the way the story is acted out, the students do not notice how they use and acquire the target items. Therefore, learning is a by-product in TPRS.

3) Reading. At this step, the students read the same story as in the previous step, discuss it and translate it. Next, follow-up activities are done, which may include writing activities (e.g., writing a different end for the story), quizzes and relating the text with grammar.

Although these steps can be adapted for very young learners, TPRS has been mostly explored within the context of older learners (Varguez, 2009; Dziedzic, 2012; Watson, 2009; Perna, 2007, Spangler, 2009; Beal, 2011; Armstrong, 2008; Castro, 2010; Roberts \& Thomas, 2014). In one of the rare studies conducted with very young learners Demir and Çubukçu (2014) demonstrate that the six-year old Turkish children who were taught the target vocabulary through TPRS were statistically more successful on the recall of the lexical knowledge than the children who were taught through communicative approaches. However, they do not state what vocabulary knowledge (receptive or productive) has been assessed in their study. Moreover, the authors do not provide any details on how exactly TPRS and the Communicative approach were implemented and what techniques were used to ensure the distinguished instruction of two groups. Some activities may be used both in TPRS and communi- cative classrooms (e.g. acting out, question-answer), but implemented in different ways. That is, the techniques can be identical or similar in nature; but the underlying methodological principles adopted by the teachers can cause differences in their classroom implementations.

$\mathrm{Li}$ in her study concludes that TPRS instruction in kindergarten is highly effective as it produces more considerable immediate effect and leads to better long-term recall of vocabulary than other approaches due to the fact that 'stories are connected with physical actions, which provide a number of traces to recall the memory' (2013: 8). Thus, repeated movements help the students remember the stories and the vocabulary they include. In addition, the author states that TPRS positively affects the general fluency and accuracy of very young learners.

It is apparent that the use of TPRS with very young learners and its possible effects on their L2 vocabulary acquisition are not sufficiently explored. The current study makes an attempt to fill these gaps by adapting the stages of storytelling in this approach to use in a kindergarten setting to investigate its impact on very young learners' L2 English receptive and productive vocabulary acquisition.

\section{METHODOLOGY}

\section{Participants and Setting}

The study was conducted with 19 four-year-old children who attended the same class of kindergarten in a private school in Istanbul, Turkey. All of the subjects were native speakers of Turkish and had been receiving English instruction for 6 months at the time of data collection.

The kindergarten where the study was conducted follows a bilingual educational system as of age 4 which aims to raise bilingual speakers through constant exposure to English language. $70 \%$ of the curriculum is done in English while 30\% is done in Turkish. Two homeroom teachers are present in each class at all times - a Turkish teacher, teaching Turkish, Maths and Science, and an English teacher who is either a native speaker of English or a non-native speaker of English with limited Turkish L1 background. The curriculum follows the principles of content-based approach: English is a means to teach Maths, Science, and Art.

In the class of four-year-olds where the present study was conducted, English was taught 13 hours a week in two to three 40-minute sessions every day.

\section{Materials}

The current study used the storybooks published by 'Raintree' ('Engage Literacy' series). The storybooks of this series are included into the English curriculum of age 4 students at this kindergarten, and are acknowledged to be cognitively and developmentally age-appropriate by the school's administration. Therefore, these materials were selected due to availability factor and the fact that the format was already familiar to the participants of the study. The series provides a variety of books for different levels which are presented in different bands (Dale, 2012; Giulieri, 2012). The 'red band' 
is recommended for four to five-year-olds, and was consequently selected for the study. The storybooks of this level are short, and the language is simplified to match the learning needs of very young learners.

The following steps were taken in order to select storybooks and target vocabulary for the study:

1) 15 storybooks of the red band were screened in order to detect potential target vocabulary. At this step, the main criteria of selection were the concreteness of the vocabulary and unfamiliarity. Whether an item would be familiar or not to the students was judged by cross-checking with the English curriculum of the preschool. It was decided to select concrete words only, because very young learners acquire them much easier than abstract items, as they are not capable of abstract thinking yet (Brewster et al., 2002; Cameron, 2001; Bourke, 2006; Huitt \& Hummel, 2003). As a result, 37 concrete and unfamiliar vocabulary items were initially identified in the storybooks.

2) The frequencies of these 37 items in the children's language were checked via 'Lextutor' (Cobb, 2017), which is an open-access online tool that can perform multiple functions, such as calculating the frequencies of the particular vocabulary items in adults' and children's language. After the frequency check, only the items that were identified by 'Lextutor' as belonging to the first 1500 frequent words of the children's language (first six sets of 250 words) were selected as target vocabulary.

This particular cut-off point was set, as 1500 words is the volume of vocabulary of a typical four-year-old child (Stahl, 1999). Even though this statement concerns the vocabulary in L1, due to the school's bilingual context and parallelism of English and Turkish languages in the curriculum, this number can be considered as an ultimate goal for this age group. Therefore, the potential target words frequency was limited to first 1500 words of children's language.

As a result, the amount of target vocabulary was reduced to 28 items.

3) The vocabulary items sorted in the previous step with the help of 'Lextutor' were cross-checked with one of the children's dictionaries - Macmillan Children's Dictionary (Barraclough, 2001), to compose the final list of target vocabulary items. Children's dictionaries are developed on the basis of corpora of children's written and oral language, and the frequency lists informed by these corpora (Cignoni et al., 1996). Thus, children's dictionaries usually include most frequent words of children's language, and therefore can serve as additional measure to verify the frequency of the target vocabulary. Besides, research has shown that children's word use differs semantically from that of adults to a considerable extent (Binder et al., 2015). Therefore, a dictionary developed specifically for children was selected in the current study, and the items that were not presented in that dictionary were eliminated, leaving 16 items remained.

4) The storybooks containing at least two items of the target vocabulary identified previously were eventually chosen as material for the study. As a result, five storybooks ('Little Sam', 'Little Zebra', 'To the Moon', 'Cooking pancakes', and 'My Big Sandwich') were selected, each including two or three vocabulary items, with the total amount of 12 items.

Other than storybooks, the treatment also included the use of flashcards, props, and videos depicting the target vocabulary at different stages of TPRS instruction in order to facilitate comprehension, attract the students' interest and keep the class motivated.

\section{Measures}

Assessment measures included productive and receptive pretests and posttests given before and after the treatment at the beginning and the end of each week respectively. Each posttest was administered once more two weeks after the end of the weekly treatment to test retention. Each test was constructed as picture vocabulary measure since the participants were illiterate, and was made up of two parts: productive and receptive. The productive part tested the ability of students to name a presented picture depicting a target word (one picture was provided for each productive test item). The participants were presented the illustrations of target words and expected to answer the question 'What is this?' On the other hand, the receptive one assessed the knowledge of the same target vocabulary tested in the productive section in a different manner. This time students were shown four pictures among which one represented the target vocabulary item and three others were the non-target vocabulary items used as distractors.

All the tests in the study were conducted in individual sessions with participants. Each participant was tested separately in a quiet room, and the test took the form of a game: the questions were asked in a playful manner, and children received stickers for correct answers. This process was repeated for each student on every test occasion (pre-, post- and delayed posttest) in each cycle of treatment. As there have been five cycles of treatment (see section 2.4) and three tests in each of them, every student has been tested 15 times in total. As each individual session took about five minutes, 75 minutes were spent on every participant's assessment throughout the study. The reason for individual data collection is that it would be impossible to do it with the whole class. As the testing was oral, all of the children would have to speak at the same time and would thus affect the answers of each other, making the results invalid. Moreover, it would be very hard to keep track of the answers of every student.

\section{Treatment}

The treatment was carried out in the spring semester of 2016-2017 school year with four-year-old children, integrated into the regular English lessons the class was receiving. The permission to collect data from these learners was taken from the institution; in addition, the parents were informed on the purposes of the study and subsequently its results. 
The treatment, as well as data collection and analysis were carried out by the English teacher-researcher of the participating class.

The implementation of TPRS in the current study follows the general principles and pillars of the method. However, some of its techniques were adapted considering the characteristics of very young learners as shown in the sample lesson plan (see Appendix A).

The study consisted of five cycles of treatment, with each one being based on one story and aiming at teaching the vocabulary from it. Every cycle of treatment lasted for one week. The procedure for every cycle followed the same order: pretest - treatment (implementation of the lesson plans prepared based on the storybook of the week following TPRS principles) - immediate posttest (identical to the corresponding pretest) and delayed posttest. The study used such a design due to the fact that each week of the treatment was dedicated to different storybook teaching different vocabulary items, which were encountered only during the week of teaching. The target items taught during a certain week would not appear anywhere during the other weeks of treatment implementation. Therefore, a single pre- and posttest including all target items could not be implemented prior to and after the weeks of treatment. Moreover, a single test including all the target vocabulary would be very age inappropriate to administer.

Therefore, it took seven weeks to complete data collection for the study. The treatment sessions were carried out every day from Monday to Friday, lasting for one teaching hour each day. That is, in total five teaching hours a week were devoted to each story, which included three steps of TPRS instruction. Thus, the first two hours - one on Monday and one on Tuesday - were spent on 'establishing the meaning' stage; the target vocabulary was introduced and pre-taught with the help of flashcards, repetition, games, chants, gestures, and PQA sessions, in which students were asked personal questions related to the topic. As for PQA sessions, they were kept short due to limited attention span of the participants.

'Asking a story' stage was implemented during the next two hours (the first one on Wednesday and the second one on Thursday). During the third hour of the weekly treatment on Wednesday the teacher-researcher told the story narrated in the target storybook. The storytelling process included the use of props, real objects and authentic sounds to create positive learning environment and increase the meaningfulness. Circling technique was used to ensure repetition of the target items and regular comprehension checks. As each story contained only two or three target words, which were on average repeated twice throughout the text, the circling questions were asked each time after a target word would appear. Furthermore, no more than four questions were asked in these stages in order to keep the class focused and motivated. These were two yes/no, one either/or and one wh- question.

The storytelling would also include creative questions that might reveal different answers to ensure students' involvement, attract their interest and provide repetition of target vocabulary.
For example (from the session in which the storybook 'Little Sam' was used):

Researcher: Sam goes to the bedroom. What will he do in the bedroom?

Learners: Sleep, play with toys, watch TV... (different answers are possible)

During the whole lesson hour the students would sit in a circle, listen to the story and participate by answering the questions in circling sessions.

The fourth hour of a TPRS treatment involved telling the same story, however, this time the students acted it out as told by the teacher. Volunteering students were picked as actors and they did the physical movements and said the lines of the characters, repeating after the teacher. A lot of different props and real objects were used during this step to keep the students engaged and motivated. Circling technique and creative questions were used during the whole period to get multiple repetitions of the target vocabulary and comprehension checks, just like it was done during the previous lesson hour.

Finally, the fifth hour of the treatment that was carried out on Friday was devoted to the third stage of TPRS process - reading. Following Gil (2015), this stage was adapted considering the participants' characteristics. This lesson consisted of reading aloud session, in which the teacher read the same story, this time using the storybook, to the students. The class would sit in a circle and listen to the story read by the teacher, who would hold the book facing the students so that they could see the pictures. Then the class did extension activities including crafts, songs, games, and creating a new end for the story. A different combination of two of these activities was used in every cycle of the treatment.

All the sessions of the treatment were video recorded in order to ensure the validity of TPRS steps implementation and collect additional qualitative data on the application of this methodology with very young learners.

\section{Data Analysis}

The data collected was analyzed using descriptive statistics due to the nature of the study that involves small sample size, two to three target vocabulary items taught in each cycle of the treatment, and very short tests including four to six questions. Data analysis included calculation of the mean scores for each of the tests, and of the percentage of the participants who responded correctly to productive and receptive questions before and after the treatment.

The participants received 1 point for the correct answers on each test. The aim of the treatments given during weeks 1,2 , and 5 was to teach two vocabulary items. The tests of these weeks included four questions on target words (one receptive and one productive question for each of the two words). Therefore, the maximum score the students could receive on these tests was 4. As for the weeks 3 and 4, three vocabulary items were taught in each of them. Thus, the tests of these weeks comprised six questions on target words, and the maximum score to be obtained was 6 . 


\section{RESULTS}

\section{A Short-Term and a Long-Term Effect of TPRS on Receptive and Productive L2 Vocabulary Acquisition}

The findings of the study advocate for the success of the treatment in the recall of the target vocabulary. As Table 1 demonstrates, the mean scores of both receptive and productive immediate posttests are considerably higher than those of corresponding pretests in all weeks. These results suggest that TPRS had a short-term effect on L2 receptive and productive vocabulary acquisition.

As seen from Table 1, the mean scores of all receptive pretests were above zero, ranging from 0.05 to 0.31 , while all the respective productive test items were failed. There could be several possible reasons for these unexpected outcomes. First of all, having four options to point at on the receptive questions of the test, the students have $25 \%$ chance of guessing the correct one, without actually possessing the knowledge of the word. Thus, it is possible that these answers were incidental. Another reason could be that some of the target words were a part of the students' receptive knowledge, but not productive knowledge yet. In the view of this second possibility, the target words that were answered correctly at the receptive questions of the pretests should have been excluded from the study. However, this was not done due to very few number of target vocabulary from each storybook used in the study. Excluding the aforementioned items would simply deprive the study of data. Yet, we would exclude such items from the analysis if any of these target words were part of any participants' productive knowledge in pre-tests, or known by all participants in receptive pre-tests, or known by a certain participant in every week' pre-test in a stable way.

The results presented in Table 1 also confirm the longterm effects of the TPRS treatment on receptive knowledge of L2 vocabulary, as the mean scores remained the same or even increased. Even though the productive results showed a slight decrease on the delayed posttests, the evidence still provides support in favor of the long-term effects of TPRS on productive vocabulary acquisition. Due to the difficulty of productive learning full retention would be nearly impossible, especially taking into account the time period between the administrations of immediate and delayed posttests and the specifics of the participants. Therefore, the decrease in the mean scores of productive posttests of Weeks 1, 2, and 5 (see Table 1) may be a result of a natural process of a gradual L2 vocabulary attrition under conditions of complete non-encounter. Despite of it, the percentages of students, who were able to produce the target words on the delayed posttests, were still high. Even the most challenging item for retention - lettuce - was produced by $63 \%$ of the participants (see Table 2), which is still a considerable improvement in comparison with productive pretest results. The other target words were produced by higher percentages of participants, therefore, the positive effect of the treatment was observed.

Interestingly, four of the items, namely river, beach, shop and spoon that could not be produced immediately by some of the participants could be retained on the delayed tests by more of the participants (see Table 2). Such results were obtained despite of the fact that these words were neither encountered by nor practised with the students in any way as part of the classroom activities after the administration of immediate posttests. This might have been caused by children's tendency to repeat the words they newly encounter as a natural part of their acquisition process (Yule, 2010). Shintani and Ellis (2014) observed in their study that young children were playing with the learnt vocabulary in their private speech and this situation was unintentionally creating an opportunity for additional practice. The participants of our study might have practised the production of the target vocabulary by themselves outside the classroom settings, for example, singing the songs on target vocabulary that were played in the classroom at home. On the other hand, it should also be noted that participants' performance might have been affected by factors like tiredness or carelessness on the day of the immediate posttest. Having considered the cognitive and affective characteristics of very young learners, this reason seems quite possible to explain this finding. To sum up, the treatment was able to demonstrate the long-term effects on the production of vocabulary items by most participants.

\section{Benefit to Receptive and Productive Vocabulary Learning}

The answer for the second research question of the study, Which type of lexical knowledge, receptive or productive, benefits from TPRS instruction more in the context of very young learners' L2 vocabulary acquisition? is also revealed by the mean scores presented in Table 1 . The Table shows that the means of the receptive tests are higher than the means of the productive tests on both immediate and delayed administrations of each week. It is clear that receptive learning is more successful than productive learning in all weeks of treatment.

Table 1. Means of the receptive and productive tests conducted throughout the study

\begin{tabular}{|c|c|c|c|c|c|c|}
\hline \multirow[t]{2}{*}{ Weeks } & \multicolumn{2}{|c|}{ Pretest } & \multicolumn{2}{|c|}{ Immediate posttest } & \multicolumn{2}{|c|}{ Delayed posttest } \\
\hline & $\begin{array}{c}\text { Receptive } \\
\text { mean }\end{array}$ & $\begin{array}{l}\text { Productive } \\
\text { mean }\end{array}$ & $\begin{array}{c}\text { Receptive } \\
\text { mean }\end{array}$ & $\begin{array}{l}\text { Productive } \\
\text { mean }\end{array}$ & $\begin{array}{l}\text { Receptive } \\
\text { mean }\end{array}$ & $\begin{array}{l}\text { Productive } \\
\text { mean }\end{array}$ \\
\hline Week $1 *$ & 0.05 & 0 & 1.95 & 1.84 & 2.00 & 1.52 \\
\hline Week $2 *$ & 0.21 & 0 & 1.95 & 1.63 & 2.00 & 1.58 \\
\hline Week $3 * *$ & 0.26 & 0 & 2.95 & 2.53 & 2.95 & 2.68 \\
\hline Week $4 * *$ & 0.31 & 0 & 3.00 & 2.63 & 2.95 & 2.63 \\
\hline Week $5^{*}$ & 0.16 & 0 & 2.00 & 1.53 & 2.00 & 1.31 \\
\hline
\end{tabular}

*Maximum score equals $2, * *$ Maximum score equals 3 
Table 2. The Percentage/Number of Participants Who Responded Correctly to Receptive and Productive Questions Throughout the Study

\begin{tabular}{|c|c|c|c|c|c|c|c|}
\hline \multirow[t]{2}{*}{ Week } & \multirow[t]{2}{*}{$\begin{array}{l}\text { Target } \\
\text { words }\end{array}$} & \multicolumn{2}{|c|}{ Before the treatment (pretest) } & \multicolumn{2}{|c|}{$\begin{array}{l}\text { After the treatment } \\
\text { (immediate posttest) }\end{array}$} & \multicolumn{2}{|c|}{$\begin{array}{l}\text { After the treatment (delayed } \\
\text { posttest) }\end{array}$} \\
\hline & & $\begin{array}{l}\text { Receptive } \\
\text { test \% (N) }\end{array}$ & $\begin{array}{l}\text { Productive } \\
\text { test } \%(N)\end{array}$ & $\begin{array}{l}\text { Receptive } \\
\text { test \% (N) }\end{array}$ & $\begin{array}{l}\text { Productive } \\
\text { test } \%(N)\end{array}$ & $\begin{array}{l}\text { Receptive } \\
\text { test \% (N) }\end{array}$ & $\begin{array}{l}\text { Productive } \\
\text { test \% (N) }\end{array}$ \\
\hline \multirow[t]{2}{*}{ Week 1} & Kitchen & $10(2)$ & $0(0)$ & $100(19)$ & $89(17)$ & $100(19)$ & $68(13)$ \\
\hline & Bathroom & $0(0)$ & $0(0)$ & $95(18)$ & $95(18)$ & $100(19)$ & $84(16)$ \\
\hline \multirow[t]{2}{*}{ Week 2} & River & $10(2)$ & $0(0)$ & $95(18)$ & $79(15)$ & $100(19)$ & $89(17)$ \\
\hline & Grass & $10(2)$ & $0(0)$ & $100(19)$ & $84(16)$ & $100(19)$ & $74(14)$ \\
\hline \multirow[t]{3}{*}{ Week 3} & Moon & $16(3)$ & $0(0)$ & $100(19)$ & $95(18)$ & $100(19)$ & $89(17)$ \\
\hline & Beach & $0(0)$ & $0(0)$ & $95(18)$ & $63(12)$ & $95(18)$ & $79(15)$ \\
\hline & Shop & $10(2)$ & $0(0)$ & $100(19)$ & $95(18)$ & $100(19)$ & $100(19)$ \\
\hline \multirow[t]{3}{*}{ Week 4} & Spoon & $10(2)$ & $0(0)$ & $100(19)$ & $89(17)$ & $100(19)$ & 95 (18) \\
\hline & Bowl & $10(2)$ & $0(0)$ & 100 (19) & $95(18)$ & 100 (19) & 95 (18) \\
\hline & Pan & $10(2)$ & $0(0)$ & 100 (19) & $79(15)$ & $95(18)$ & 74 (14) \\
\hline \multirow[t]{2}{*}{ Week 5} & Knife & $10(2)$ & $0(0)$ & 100 (19) & $79(15)$ & 100 (19) & $68(13)$ \\
\hline & Lettuce & $5(1)$ & $0(0)$ & 100 (19) & 74 (14) & 100 (19) & $63(12)$ \\
\hline
\end{tabular}

In support of this, Table 2 shows that nine target words out of twelve were identified correctly by $100 \%$ (19) of participants on the receptive questions of immediate posttest, and the remaining three words by $95 \%$ (18). Moreover, ten vocabulary items out of twelve were retained by all participants on receptive part of delayed posttest. However, the percentages of children with productive knowledge on both immediate and delayed tests were lower than those of children with receptive knowledge in almost all of the target words. As the study does not involve any statistical analysis, we do not know if the differences between these percentages or receptive and productive means are statistically significant or not. However, it is evident that the productive knowledge decays in a larger extent than the receptive knowledge.

\section{The Challenging Nature of the Vocabulary Items and Their Frequencies}

The results of the posttests also demonstrated that some vocabulary items were more challenging for children to acquire than the others. Thus, pan (target word in Week 4) turned out to be the most challenging item of the cycle as four students failed to produce it on the immediate posttest, and the delayed posttest showed even lower results. The remaining target words were acquired much better: the words bowl and spoon (the remaining target items in Week 4) were not produced by 1 and 2 students respectively on the immediate posttest, while they were receptively acquired by everyone; delayed posttest scores were similar - there was one participant who failed to produce the target item in the case of each word. The frequency of these words in children's language may be the explanation for these findings, as the word pan is used less frequently than spoon or bowl. Moreover, the concepts of spoon and bowl are familiar to our participants from early childhood as they use those utensils every day; whereas pan is mostly used by their parents and therefore, may not relate to the immediate environment of the children.
However, the challenging nature of a word cannot always be explained by its frequency. For example, in the case of item beach (Week 3), seven students failed to produce it on the posttest; while the other items taught in Week 3 - moon and shop-were receptively acquired by all and produced by 18 of the participants (see Table 2). This finding cannot be explained by its frequency, as the word beach is used as frequently as shop, and even more frequently than moon (Cobb, 2017). Moreover, each target vocabulary item was taught through the same techniques of TPRS and practised with the same amount of repetition during the sessions. Therefore, we consider this result as unexpected.

\section{DISCUSSION \& CONCLUSION}

The results of this study supported the effectiveness of TPRS in teaching L2 vocabulary to preschoolers. TPRS treatment was found to have a short-term and a long-term effect on the acquisition of receptive and productive L2 vocabulary by very young learners. These findings are in line with the results of the studies of Gil (2015), Li (2013), and Demir and Çubukçu (2014). These scholars explain the positive impact of TPRS on the lexical competence of preschoolers with the variety of teaching techniques of the method and with comprehensible and repetitive input it presents.

Moreover, our study suggests that TPRS had a beneficial effect due to its central technique - storytelling, which provided ground for various activities, introducing the target words in a meaningful and familiar context. The visualizations and props provided by the stories bolstered the students' interest and motivation. Similar conclusions concerning storytelling technique were made by Elley (1989), Penno et al. (2002), Blok (1999), Collins (2004), Soleimani and Akbari (2013), and Wasik and Bond (2001). Thus, the study supports the existing research on storytelling use in teaching a foreign language, and demonstrates its effectiveness within TPRS methodology. 
The implementation of TPRS clearly had more effect on receptive than productive learning of vocabulary. This finding suggests that receptive vocabulary is learnt faster and easier than the productive vocabulary. The positive effect of storytelling on receptive vocabulary acquisition was also found by Abasi and Soori (2014) and Tunçarslan (2013). There can be several reasons for such findings. First of all, learners gain precise knowledge of the spoken and written forms in order to acquire a word productively. This task could be especially challenging if the L1 and L2 systems have significant differences. While receptive knowledge requires ability to recognize the spoken and written forms of a word and extract its meaning, being able to do these would not be enough for productive learning as it involves a larger body of knowledge including correct pronunciation, spelling, and grammatical, colloquial and stylistic uses of words. Moreover, receptive use is encountered much more often in the classroom, and thus, this practice effect can benefit receptive learning. Nation (2000) suggests another explanation for this situation: L1 and L2 are more likely to share the knowledge of meaning rather than the knowledge of form, therefore, acquisition of productive knowledge is more difficult. Finally, following the principles of Natural approach, TPRS does not force the students who have not overcome the silent period stage yet to speak. The repetition of the target vocabulary is mainly provided by the teacher in the course of PQA, circling and other techniques used in the method. Thus, the participants mostly heard the target words repeated by teacher during the implementation phase instead of producing them; therefore, it was most often the receptive learning that took place. This may explain the higher performance of the participants on the receptive tests.

\section{Pedagogical Implications}

Based on the results of the study some significant implications can be made regarding how TPRS can be used with very young learners. During the implementation of this method it was noticed that the students enjoyed the classes taught with the usage of TPRS methodology. They were motivated to act the stories out, listen to the stories performed by the teacher with the use of props, take part in the games for vocabulary practice and watch the videos. Most of the activities used were able to engage the students and evoke their interest. It can be concluded that TPRS methodology is appropriate to use with very young learners, as it provides them with concrete concepts, familiar context, and plenty of kinesthetic and explorative activities that are essential for their learning. Besides, the element of play and visualization create stress-free environment and contribute to the enthusiasm of the students (Ormond, 2010; Widodo, 2005; Wright et al., 2007; Castro, 2002).

Therefore, it can be suggested that TPRS is a suitable methodology for very young learners and can be applied in EFL curricula in kindergartens. Moreover, based on the personal observations of the teacher-researcher it was concluded that storytelling implementation within TPRS attracted the interest of the students and motivated them more than the application of this technique in isolation with kindergar- ten students of previous years. Students seemed to be more involved, more willing to participate in the activities provided in TPRS sessions, which enhanced the positive learning environment of the classroom.

However, some adaptations would still be needed while applying TPRS with very young learners due to their specific learning characteristics. The first concern is the excessive use of questions of the same type (PQA and circling technique) in TPRS. Though these questions are very important in the methodology design as they ensure multiple repetitions of the target items, asking similar questions in a row to very young learners may result in attention and interest loss, which occasionally happened during the implementation phase of the study. In order to solve this problem, the sets of circling questions can be divided into sections of 1-2 questions each, which would be evenly asked at different points of the story, thus varying the questions with narration. Asking only 1-2 questions at a time would help the teacher to keep the students engaged.

As for PQA technique used during the stage of establishing the meaning, it should be kept shorter and carried out in a more organized way, e.g. fast transitions from one question to another need to be done to prevent the loss of focus.

Another feature of TPRS that needs adaptation is the use of props. According to some early philosophers whose ideas became influential in early childhood education like Froebel, Montessori, Dewey and Piaget, the whole learning environment of children should approximate the reality to the maximum extent. Hence, visuals and real life objects should be widely used during the teaching process. They are normally included into standard design of TPRS methodology; however, in application with very young learners the numbers of visuals/props used have to be much greater. This will emotionally appeal to them and facilitate their learning. A considerable use of props in the current study made the students very enthusiastic and active, lowered the affective filter and motivated them, and possibly contributed to acquisition.

In order to ensure learning and provide stimulating learning environment while teaching very young learners it is important to maintain a high level of variety (Brewster et al., 2002). In the current study various flashcard games, songs, videos and other activities, like action games and crafts were used in each teaching cycle, resulting in students' interest and active involvement in the process of learning.

Gil (2015) emphasizes the necessity of adaptation of the third step in teaching with TPRS - reading. As very young learners are illiterate, it is not possible for them to perform any activities with reading or writing; with these students, the skills involved are listening and speaking. Therefore, most of the activities that are normally suggested at this stage (reading and translating the story, rewriting it, taking quizzes) have to be eliminated. Instead, it is offered to carry out a read-aloud session (when the story is read by the teacher) and have students improvise and create a new end for the story. This stage can also be varied with other follow-up activities, such as songs, crafts, and games. In the current study reading stage was applied following the suggestions of Gil (2015). Instead of doing activities that would require literacy, the students listened to the teacher reading a story 
and enjoyed the crafts and games used at the final session of the reading stage.

Finally, as very young learners have lower cognitive capacity than older students, it seems reasonable to teach one concept at a time and focus on concrete notions, as it is hard for kids to perceive the abstract ones. It is crucial that the teachers using TPRS in kindergarten maintain positive learning environment and keep their sessions as much enjoyable as possible, with the use of plenty of songs, games, visuals and chants in order to ensure comprehensibility and to guarantee that the students enjoy the class, pay attention and learn (Gaab, 2009).

The study has some important implications for curriculum developers as well. As mentioned earlier, The Ministry of Education of Turkey does not prescribe any particular curriculum for teaching English in kindergarten, which makes it a challenge for EFL teachers to design materials and activities appropriate for very young learners. A curriculum to be developed based on the principles of TPRS, however, could significantly facilitate teachers' work in kindergarten. To this end, the recommendations made above on adapting TPRS for this specific context and the samples of lesson plans that describe the implementation of TPRS techniques can be an inspiring guidance for all who would like to benefit from the positive effects of this approach to language teaching, and may hence extend the use of TPRS in Turkish EFL context.

\section{Limitations and suggestions for further studies}

The current study has some limitations that need to be acknowledged, too.

The main limitation of the study was the small sample size. Moreover, due to the age and characteristics of the participants the number of the vocabulary taught was very limited; hence, the tests only included a few items. These factors made it impossible to do the statistical analysis of the collected data; therefore, the significance of the results was not established statistically. Future studies may increase the size of the sample and the number of vocabulary items in order to obtain statistically significant results.

Absence of control group in the study was another limitation. Further research may replicate the study with a control group as it would help to better understand the effects of TPRS methodology on vocabulary acquisition and demonstrate the results it produced more clearly.

The duration of the study (seven weeks) may not be enough to fully guarantee the effectiveness of the method; moreover, the delayed posttests were conducted only two weeks after the end of each cycle of treatment, and therefore, may not have reflected time effect completely. Hence, it can be recommended to design a study that would consider longer duration with larger time periods between immediate and delayed posttests to get more evidence on the effect of the treatment.

All the participants of the current study were four-yearolds. However, it can be of interest to conduct a further research with older kindergarten students in order to see whether the adaptations to TPRS suggested in this study are applicable for them too, and whether the methodology is able to produce the same effect on their acquisition of L2 vocabulary.

Finally, the present study was conducted with exclusively high-frequency vocabulary. The next studies could be administered with low-frequency words in order check whether the effect of TPRS methodology is similar with this vocabulary group.

\section{REFERENCES}

Abasi, M., \& Soori, A. (2014). Is storytelling effective in improving the English vocabulary learning among Iranian children in kindergartens? International Journal of Education and Literacy Studies, 2(3), 7-11.

Armstrong, A. (2008). Fun and fluency in Spanish through TPRS: an action research project. UW-L Journal of Undergraduate Research, XI, 1-6. [Online] Available: https://www.uwlax.edu/.

Barraclough, C. (2001). Macmillan children's dictionary. Oxford: Macmillan Publishers Limited.

Beal, K.D. (2011). The correlates of Storytelling from the Teaching Proficiency through Reading and Storytelling (TPRS) method of foreign language instruction on anxiety, continued enrollment and academic success in middle and high school students. $\mathrm{PhD}$ diss., University of Kansas, Lawrence, KS. [Online] Available: https:// kuscholarworks.ku.edu/.

Benjamin, A. \& Crow, J.T. (2012). Vocabulary at the core: teaching the common core standards. New York: Eye On Education.

Binder, K.S., Magnus, B., \& Lee, C. (2015). To tell a morphologically complex tale: investigating the storytelling abilities of children and adults with low literacy skills. Reading and Writing: An Interdisciplinary Journal, 28(7), 1029-1049.

Blok, H. (1999). Reading to young children in educational settings: A meta-analysis of recent research. Language Learning, 49, 343-371.

Bourke, J. (2006). Designing a topic-based syllabus for young learners. ELT Journal, 60(3), 279-286.

Braunstein, L. (2006). Adult ESL learners' attitudes towards movement (TPR) and drama (TPR Storytelling) in the classroom. CATESOL, 18(1), 7-20.

Brewster, J., Ellis, G., \& Girard, D. (2002). The primary English teacher's guide. Harlow: Pearson Education Limited.

Cameron, L. (2001). Teaching languages to young learners. Cambridge: Cambridge University Press.

Castro, M. (2002). The magic world of storytelling: some points for reflection. PROFILE: Issues in Teachers' Professional Development, 3, 52-54.

Castro, R. (2010). A pilot study comparing Total Physical Response Storytelling with the Grammar-Translation teaching strategy to determine their effectiveness in vocabulary acquisition among English as a second language adult learners. MA thesis, Dominican University of California, California. [Online] Available: http://scholar.dominican.edu/cgi/viewcontent.cgi?arti$\mathrm{cle}=1123 \&$ context $=$ masters-theses . 
Cignoni, L., Lanzetta, E., Pecchia L., \& Turrini, G. (1996). Children's aid to a children's dictionary. In Proceedings of the Seventh EURALEX International Congress on Lexicography, edited by M. Gellerstam et al., 659-666. Goteborg, Sweden: Novum Grafiska AB.

Cobb, T. VP-Kids v.9 [computer program]. Accessed 15 Sept 2017 at http://www.lextutor.ca/vp/kids.

Collins, M. F. (2004). ESL preschoolers' English vocabulary acquisition and story comprehension from storybook reading. PhD diss., Boston University, Massachusetts. Abstracts International, 65(03), 824.

Cooper, P. J., Collins, R., \& Saxby, M. (1992). The power of story. Melbourne: MacMillan.

Dale, J. (2012). To the moon. Oxford: Raintree.

Davidheiser, J. C. (2001). The ABCs of TPR Storytelling. Dimension, 2001, 45-53.

Demir, Ş., \& Çubukçu, F. (2014). To have or not to have TPRS for preschoolers. Asian Journal of Instruction, 2(1), 186-197.

Donaldson, M. (1978). Children's minds. London: Routledge.

Dziedzic, J. (2012). A comparison of TPRS and traditional instruction, both with SSR. The International Journal of Foreign Language Teaching, 7(2), 4-6.

Elley, W. B. (1989). Vocabulary acquisition from listening to stories. Reading Research Quarterly, 24(2), 174-187.

Ellis, N.C. \& Beaton, A. (1993). Factors affecting the learning of foreign language vocabulary: imagery keyword mediators and phonological short-term memory. Quarterly Journal of Experimental Psychology, 46A, 533-558.

Gaab, C. (2009). Managing meaningful interaction in the elementary language classroom. The International Journal of Foreign Language Teaching, 5(2), 18-20.

Gil, V.M. (2015). Is the Teaching Proficiency through Reading and Storytelling (TPRS) approach an efficient methodology for infant education students? MA thesis, University Jaume I, Castello de la Plana, Spain. [Online] Available: http://repositori.uji.es/xmlui/handle/10234/146092.

Giulieri, A. (2012). Cooking pancakes. Oxford: Raintree.

Huitt, W., and J. Hummel. (2003). Piaget's theory of cognitive development. Educational Psychology Interactive. [Online] Available: http://www.edpsycinteractive.org/ index.html.

Jebeli, M. (2012). Effects of Teaching Proficiency through Reading and Storytelling on Iranian students' vocabulary acquisition. MA thesis, University of Technology, Malaysia. [Online] Available: http://eprints.utm.my.

Krashen, S. (1981). Second language acquisition and second language learning. Oxford: Pergamon Press.

Li, N. (2013). Is TPRS an effective method for teaching Chinese as a foreign language among young learners of beginning levels? Paper presented at The European Conference on Education, Brighton, UK, July.

Morrison, S. (1997). Fundamentals of early childhood education. (Third edition). Ohio: Merrill Prentice Hall.

Nation, I.S.P. (2000). Learning vocabulary in another language. Cambridge: Cambridge University Press.
Ormond, J. E. (2010). Educational psychology: developing learners. Basil Prentice Hall: Pearson Publishing.

Penno, J. F., Wilkinson, I. A. G., \& Moore, D.W. (2002). Vocabulary acquisition from teacher explanations and repeated listening to stories: do they overcome the Matthew effect?" Journal of Educational Psychology, 94, 22- 33.

Perna, M. (2007). Effects of Teaching Proficiency through Reading and Storytelling versus traditional, versus initial instruction with primary-, reinforced by secondary- perceptual strengths, on the vocabulary- and grammar-Italian- language achievement test scores, and the attitudes of ninth and tenth graders. PhD diss., St. John's University, New York, NY. [Online] Available: ProQuest Dissertations and Theses database.

Ray, B., \& Seely, C. (2004). Fluency through TPR Storytelling ( $4^{\text {th }}$ ed.). Bakerfield, CA: Command Performance Language Institute.

Reilly, V., \& Ward, S.M. (2003). Very young learners. (Eighth edition). New York: Oxford University Press.

Roberts, B., \& Thomas, S. (2014). Center for Accelerated Language Acquisition (CALA) test scores: another look at the value of implicit language instruction through comprehensible input. International Journal of Foreign Language Teaching, 10(1), 2-12.

Schmitt, N. (2000). Vocabulary in language teaching. Cambridge: Cambridge University Press.

Shintani, N., \& Ellis, R. (2014). Tracking 'learning behaviours' in the incidental acquisition of two dimensional adjectives by Japanese beginner learners of L2 English. Language Teaching Research, 18(4), 521-542. http://dx.doi.org/10.1177/1362168813519885.

Soleimani, H., \& Akbari, M. (2013). The effect of storytelling on children's learning English vocabulary: A case in Iran". International Research Journal of Applied and Basic Sciences, 4(11), 4005-4014.

Spangler, D.E. (2009). Effects of two foreign language methodologies, communicative language teaching and Teaching Proficiency through Reading and Storytelling, on beginning-level students' achievement, fluency, and anxiety. PhD diss., Walden University, Minneapolis, MN. [Online] Available: ProQuest Dissertations and Theses database.

Stahl, S. A. (1999). Vocabulary development. Brookline, MA: Brookline Books.

Sutijono, A. A. (2014). The effect of Teaching Proficiency through Reading and Storytelling (TPRS) on the vocabulary achievement of elementary school students. MA thesis, Widya Mandala Catholic University, Surabaya, Indonesia. [Online] Available: http://repository.wima.ac.id/5227/.

Tabors, P.O., \& Snow, C.E. (2013). English as a second language in preschool programs. In Educating Second Language Children, edited by F. Genesee, 103-125. New York: Cambridge University Press.

Tunçarslan, H. K. (2013). The effect of short stories on teaching vocabulary to very young learners (aged 3-4 years): a suggested common syllabus. MA thesis, Gazi University, Ankara, Turkey. [Online] Available: https://tez.yok. gov.tr. 
Varguez, K.Z. (2009). Traditional and TPR Storytelling instruction in the beginning high school Spanish classroom. The International Journal of Foreign Language Teaching, 5(1), 2-11.

Wasik, B. A., \& Bond, M.A. (2001). Beyond the pages of a book: interactive book reading in preschool classrooms. Journal of Educational Psychology, 93(2), 243-250.

Watson, B. (2009). A comparison of TPRS and traditional foreign language instruction at the high school level. International Journal of Foreign Language Teaching, 5(1), 21-24.

\section{APPENDIX A.}

Weekly lesson plans for teaching L2 vocabulary through TPRS in preschool

\section{Week 1.}

The title of the book: "Little Sam".

Target vocabulary items: kitchen, bathroom.

Steps of TPRS:

1. Establishing the meaning, part 1.

Materials used in this stage: flashcards depicting bathroom and kitchen, two videos teaching the target vocabulary, coloring worksheet of kitchen and bathroom, smart board.

Time: 1 hour, Monday

\section{Activity 1. Introduction of new Vocabulary}

Teacher (T) draws a house on the board depicting separate squares - rooms. T: "This is my house. And in my house I have a ...(shows the flashcard of kitchen)... kitchen!" $\mathrm{T}$ repeats the word several times.

T asks the class: "What do we do in the kitchen?" and elicits answers. Then, T encourages the students (SS.) to sing a kitchen song with her, while doing the cooking movement - pretending to stir something. After that, T sticks the flashcard of kitchen on the board and repeats the word again.

T says: "And also in my house I have a ... (shows the flashcard of bathroom) a bathroom!" T repeats the word 'bathroom' several times. Then, T elicits actions that are done in the bathroom (brushing teeth, washing hands etc). Then, T encourages the SS to sing a bathroom song with her, while doing the washing movement. Finally, T sticks the flashcard of bathroom on the board and repeats the word again.

\section{Activity 2. Video}

Class watches a video 2 times; it is a song teaching rooms of the house vocabulary. (https://www.youtube.com/ watch? $\mathrm{v}=5 \mathrm{bZBJe} 1$ toiE)

$\mathrm{T}$ draws the students' attention on bathroom and kitchen demonstrated in the video and repeats these words. During the second watching, T pauses the video and asks "What is it?" pointing at bathroom and kitchen.

\section{Activity 3. Game}

SS run and touch the flashcard, named by the T
Widodo, H. P. (2005). Teaching children using a Total Physical Response (TPR) method: rethinking. Bahasa Dan Seni, 33(2), 235-248.

Wright, C., Bacigalupa, C., Black, T., \& Burton, M. (2007). Windows into children's thinking: a guide to storytelling and dramatization. Early Childhood Education Journal, 35(4), 363-369. http://dx.doi.org/10.1007/ s10643-007-0189-0.

Yule, G. (2010). The study of language. Cambridge: Cambridge University Press.

\section{Activity 4. Video}

Class watches another video, teaching the target vocabulary (https://www.youtube.com/watch?v=DR5qPNPGCmY).

\section{Activity 5. Game}

SS find a hidden flashcard and name it.

\section{Activity 6. Worksheet}

SS color the worksheet, illustrating kitchen and bathroom.

2. Establishing the meaning, part 2. Materials: see Establishing the meaning, part 1. Time: 1 hour, Tuesday

\section{Activity 1.}

T shows the flashcards of the target words, elicits the vocabulary.

\section{Activity 2. PQA}

PQA are asked:

- Do you have kitchen/bathroom in your house?

- Is your kitchen/bathroom big or small?

- What color is your kitchen/bathroom?

- What do you do in your kitchen/bathroom?

\section{Activity 3. Video}

Class watches the first video from the previous lesson again and reviews the vocabulary.

\section{Activity 4. Games}

Flashcard games are played: missing flashcard, pantomime, lip guess, flash game.

\section{Activity 5. Video}

Class watches the second video from the previous lesson again.

\section{Activity 6. Personalisation}

SS are asked to draw their own kitchen and bathroom. 
3. Asking a story, part 1 .

Time: 1 hour, Wednesday.

Materials used: paper puppets representing the main characters: Little Sam, Molly, Mum; a colourful print out of a plant; small toys - blocks; flashcards of kitchen and bathroom.

Setting: the SS sit on the carpet in a circle, the T sits at the table in front of them. There is a big box on the table with the all materials behind it, the $\mathrm{T}$ tells the story to the class, taking the necessary materials from behind the box and showing to the $\mathrm{SS}$ as the story goes on.

Below is the story told by the $\mathrm{T}$ with creative questions in italics and circling questions underlined.

Once upon a time there was a boy whose name was Sam. But Sam was a naughty little boy. He liked pushing, breaking things and he never listened to his Mum. One day little Sam went to the garden and started pulling the plant. Soon, the pot was broken and the plant fell down. Then Sam's sister Molly came. She said: 'Sam! What did you do?' And she called Mum: 'Mum, come here! Come and see little Sam!'

Then Mum came. She saw what Sam had done and got very angry.

-Little Sam! Come to me! - said Mum.

-No! No! No! - said Little Sam. And he ran away.

Where do you think Sam ran?

Little Sam went to his sister Molly's room and started throwing Molly's toys around and making a mess. Molly came and she got angry. She said: 'Sam! What did you do?' And she called Mum: 'Mum, come here! Come and see little Sam!'

Then Mum came. She saw what Sam had done and got very angry.

-Little Sam! Come to me! - said Mum.

-No! No! No! - said Little Sam. And he ran away.

Where do you think Sam ran now?

Little Sam came to the kitchen and started making everything dirty.

Is Sam in the garden now? (Class: No!)

Is he in the bathroom? (Class: No!)

Is Sam in the kitchen? (Class: Yes!)

Is Sam in the bathroom or in the kitchen? (Class: Kitchen!)

Where is Little Sam? (Class: In the kitchen!)

Molly came and saw Little Sam. She called Mum: 'Mum, come here! Come and see little Sam!'

Then Mum came. She saw what Sam had done and got very angry.

-Little Sam! Come to me! - said Mum.

-No! No! No! - said Little Sam. And he ran away.

Where do you think Sam ran now?

Now little Sam is in the bathroom.

Is Sam in the garden now? (Class: No!)

Is Sam in the kitchen? (Class: No!)

Is he in the bathroom? (Class: Yes!)

Is Sam in the bathroom or in the kitchen? (Class: Bathroom!)
Where is Little Sam? (Class: In the bathroom!)

Mum is here too. She said: 'Molly! Come and see Little Sam!' Little Sam was so dirty that Mum started washing him and Molly helped her. Now little Sam is clean and is a good boy.

4. Asking a story, part 2.

Time: 1 hour, Thursday

Materials: a plant, toys, toy kitchen utensils, plastic fruits and food, bath sponge.

Setting: T actors-volunteers among the students are chosen to play Little Sam, Molly, and Mum. T is the narrator, who tells the actors their lines, guides the actors on their actions and movements and asks the questions to the audience - class. Different parts of the classroom represent the different rooms in the story. Props are used to make the 'rooms' look more realistic.

The text of the story is equal to the one in the previous lesson

(Asking a story, part 1), however, this time it is acted out.

5. Reading

Time: 1 hour, Friday

Materials: storybook 'Little Sam' (one copy for each student); smart board, online version of the book 'Little Sam' (http://www.online.raintree.co.uk); two videos from lessons 1 and 2; magazines depicting bathroom and kitchen objects, scissors, glue sticks, craft paper.

Setting: During Activity 1 SS sit in a circle on the carpet, the $\mathrm{T}$ sits on the chair in front of them while reading the storybook to the class. For Activities 2, 3 and 4 online book reading and the following activities the SS take their seats at the tables.

\section{Activity 1. Reading.}

$\mathrm{T}$ introduces the storybook and then reads it to the class, asking the same questions, as in Asking the story lessons.

\section{Activity 2. Choral reading.}

$\mathrm{SS}$ receive the copies of the book and listen to the online version of the book, following the lines. Then choral reading is done.

\section{Activity 3. Videos.}

SS watch the videos from the previous lessons and review the vocabulary.

\section{Activity 4. Craft project.}

The class is divided into 4 groups. Each group gets magazines with the pictures of bathroom and kitchen objects. Two of the groups find and cut out the bathroom objects, the other two groups - kitchen objects. Then groups make a poster. 